\title{
Cultural Humility in Music Teacher Education: A Virtuous Vice, A Vicious Virtue
}

\author{
Hayley Janes \\ University of Toronto
}

Music teacher educators are not alone when grappling with the challenge of preparing students to navigate diversity and confront inequity and injustice. Educators and researchers from multiple disciplines face similar challenges and have responded with various approaches related to cultural multiplicity. The concept of "cultural humility" is one such approach from the health sciences (Tervalon and Murray-García 1998). I both put forward and challenge cultural humility as a process for preparing music educators to think about, work, interact, and live with cultural multiplicity. I draw on personal experiences, using a critical autoethnographic epistolary to write letters between my various selves. Existing research on cultural humility is first organized into intrapersonal and interpersonal dimensions. I then problematize the virtuous reputation of humility specifically and explore its implications for cultural humility. I suggest that cultural humility is neither "good" nor "bad" but is something to be exercised differently in different contexts.

Keywords: cultural humility, music teacher education, critical autoethnography, epistolary

\section{Preface: Critical Autoethnographic Epistolary}

Dear Reader,

Research methodology can be a story unto itself; the tale of how this critical autoethnographic epistolary ${ }^{1}$ came to be is the perfect place to start. Let us first get better acquainted. I am White, cisgender, female, able-bodied, middle-class, a settler born and raised in Canada, an English speaker, and in my mid-twenties. I am the eldest of three children whose parents were born in Canada and attended university. These identities afford me privileges with unearned benefits (Hook et al. 2017); I move, think, live, and progress comfortably within the sociocultural context in which I live. However, I write to you not from a place of comfort, but a productive place of unease.

(C) Hayley Janes. The content of this article is the sole responsibility of the author. The ACT Journal and the Mayday Group are not liable for any legal actions that may arise involving the article's content, including, but not limited to, copyright infringement. 
My sense of unease began during my music teacher education. I felt dissatisfied with what I experienced as a lack of opportunity to develop my ability to navigate cultural differences (e.g., limited opportunities for a sustained interrogation of my assumptions surrounding culture and music education). I became drawn to the health sciences concept of cultural humility (Tervalon and Murray-García 1998) because of this dissatisfaction. Simply put, cultural humility refers to engaging humbly with those who are culturally different from oneself. Humility may be understood as a quality, condition, state, or characteristic. However, I refer to the entire concept of cultural humility as a process, given that it reflects the seminal work of Melanie Tervalon and Jann Murray-García (1998), who define the medical training outcome of cultural humility as a continuous process of self-reflection and self-critique, mitigating power imbalances, and developing and maintaining mutually respectful and dynamic partnerships with the community.

Further reflection and engagement in practice have shifted my thinking toward the complexity of cultural humility, and I now find myself both drawn to and uneasy with the concept. It is not, I suggest, a straightforward concept that can just transfer to music education, given that there is a range of implications to address. I write to you with the following personal account, to propose and problematize cultural humility as a process for preparing music educators for cultural multiplicity. I do so through a critical autoethnographic epistolary.

The literature informs my choice of method. There is a disconnect between what authors in the literature emphasize about cultural humility and how scholars write about cultural humility. Despite the emphasis on engaging with personal views, assumptions, and cultural identities, existing research on the concept across disciplines either features no acknowledgment of researcher positionality (e.g., Lerner and Fulambarker 2018, Sprik and Gentile 2020) or only minimal researcher reflexivity (e.g., Jisrawi and Arnold 2018; Hurley, Kostelecky, and Townsend 2019). The focus remains outward-on the experience of participants (e.g., Cervantes and Clark 2020, Hook et al. 2013, Keselman and Awais 2018). When I first noted this disconnect, I considered how I could and if I should study cultural humility before engaging with the process myself.

I use the methodology of autoethnography, which draws upon the personal experiences, thoughts, and feelings of the researcher to illuminate, examine, and/or critique something about a particular sociocultural context of which the researcher is a part (Adams, Holman Jones, and Ellis 2015). I specifically use a critical form of autoethnography conceptualized by methodological scholars Tony Adams 
(2017), Robin Boylorn and Mark Orbe (2014), Elizabeth Mackinlay (2019), and Stacy Holman Jones (2016). Critical autoethnography uses stories and theory (Holman Jones 2016) to identify power, privilege, injustices, and inequalities in everyday life at the personal and cultural level (Adams 2017, Boylorn and Orbe 2014) by "troubling" the auto (the self), the ethno (the description), and the graphy (the writing) (Mackinlay 2019). I underpin my use of critical autoethnography with Donna Mertens' (2009) and Mirjam Held's (2019) descriptions of a transformative research paradigm ${ }^{2}$ and Zeus Leonardo's (2004) writing on critical social theory. 3 This methodological, paradigmatic, and theoretical orientation is well suited to working with cultural humility; all proceed from the assumption that injustice, inequality, and oppression are pervasive, real, formidable, social, and lived.

Perhaps you already have realized that this work is not only a critical autoethnography since I am writing to you in the form of a letter. Autoethnography has developed in response to canonical ideas about research that are considered colonial, masculine, White, positivistic, and scientific (Ellis, Adams, and Bochner 2011). Part of the response is to disrupt normative research practices and representational forms (Holman Jones, Adams, and Ellis 2013) through the use of unique modes of inquiry and expression (Wall 2006). In line with these objectives, I combine critical autoethnography with the art form of an epistolary, ${ }^{4}$ a genre of writing in which the story is told through a series of letters (Bray 2003). The intimate nature of a letter, from which its reputation as a feminist literary form emerged (Bray 2003), is suitable for communicating my inner thoughts and emotions, and the organization of these letters into an epistolary connects my thoughts and emotions with a wider audience and context. Thus, the epistolary genre, as a paradoxically private and public form (Stanley 2004), is well-positioned to meet the autoethnographer's goal-to connect self and culture.

Rather than present a single narrating self, I write my selves into this critical autoethnographic epistolary in the form of multiple letter signatories and recipients. I write letters between my selves to illustrate that I do not possess a single, temporally fixed voice, but many voices that exist across time and that interact in various ways. The overarching perspective is that of the Scholartist, whose purpose is to propose and problematize cultural humility on a broad conceptual level. The term scholartistry comes from arts-based research and refers to a merging of scholarly and artistic practices that challenge bounded categories of research, scholarship, and artistic engagement (Siegesmund 2018, Cahnmann-Taylor and Siegesmund 2018). For my purposes, the Scholartist blends the systematic and 
critical use of literature (the scholarly) with an autoethnography presented through the epistolary art form (the artistic). The personal, informal, and conversational writing makes this research on cultural humility accessible and appealing to a broad readership - an aim of both autoethnographers (Gouzouasis and Ryu 2015; Adams, Holman Jones, and Ellis 2015) and scholartists (Cahnmann-Taylor and Siegesmund 2018). In this way, I hope that readers from various backgrounds will find the correspondence that follows engaging.

The other letter signatories and recipients adopt a similar writing style, but each serves a different purpose. The Researcher proposes and problematizes cultural humility specifically within the context of music teacher education, while the Music Educator represents a link between theory and practice, abstraction and examples, and training and teaching. The Music Educator's purpose is to provide personal examples that supplement abstract discussions and connect literature to lived experience. Finally, the Student corresponds with the other letter writers to learn about cultural humility. During the progression of the epistolary, the Student raises questions and poses challenges while contributing personal examples of music teacher education that are relatable and accessible. Though these selves represent different perspectives and ways of thinking, they also overlap and intersect. They are not distinct voices but many aspects of the same individual. The Student is the Researcher, who is the Music Educator, who is the Scholartist, who is the Student, and so on because they are all me. These epistolary selves express my plural and sometimes contradictory views to illustrate the complexity of cultural humility.

The representation of my selves is further complicated by the epistolary's disruption of linearity. Letters possess a "temporal doubleness" (Tucker 1993, 423)a time at which they are written and a time at which they are read, separated by the time it takes for the recipient to receive the letter (Stanley 2004). It is questionable at what precise time self-representation occurs (Tucker 1993), especially with the merging of past and present. The epistolary you are reading is in the past: a reader of a letter always knows that "the 'moment' of its writing has gone" (Stanley 2004, 208). However, in reading a letter, the past becomes the reader's present (Stanley 2004). And when exactly are you reading these letters-as they are written, as they are read by the recipient, or at some other moment (Tucker 1993)? Are they being read aloud or in silence? These letters between my selves allow me to put my thoughts and experiences from the past in conversation with my thinking in the present, so I can approach cultural humility from multiple vantage points. 
I aim to both put forward and challenge cultural humility as a process for preparing music educators to think about, work, interact, and live with cultural multiplicity. By providing autoethnographic insights that come from one point in time, I present my multiple selves in the middle of figuring things out (Ellis and Bochner 2006). I embed literature throughout the letters, rather than write a contained literature review section, to reflect my continuous grappling with my experiences and thoughts. While resisting finality and closure, I embrace open-endedness in alignment with an autoethnographic "conception of the self (and society) as relational and processual" (Anderson and Glass-Coffin 2013, 79). Finally, in using an epistolary to structure my contemplations, I follow the tenets of arts-based research, the products of which "are closer in function to deep conversation and insightful dialogue than they are to error-free conclusions" (Eisner 2008, 7). I do not argue whether cultural humility should be dismissed or accepted within music teacher education. Rather, I suggest that a more contextual approach toward cultural humility should acknowledge its complexity and address the range of implications that may arise within music teacher education.

I write these letters for you. Judith Butler (2005) suggests the "I" is relational and comes into being because of a relation to another, to a "you." Who are you? I am who I am because of a "you" and write these letters not knowing into whose hands they may fall. As Carolyn Ellis (2000) advises, I hope you feel with the story, are engaged, evoked, and provoked while thinking about your positioning. Embrace the doubleness of identities that allows for both recipients of the letters and a recipient of the epistolary (Tucker 1993). While these letters are between my selves, in a way, they are also to you.

Sincerely,

The author

\section{Proposing Cultural Humility}

\section{Student to Researcher 5}

Dear Researcher,

I can't stand feeling under-prepared. That clammy, sinking-stomach sense of dread that I could have done more is unbearable. So unbearable, in fact, that I just have to write to you. Growing up, I participated in what I consider a "typical" North American music education: I started violin in my public-school strings program 
and eventually took private lessons, played in youth orchestras, attended summer music camps, performed in music festivals, and completed music exams. Now as a music education student in my final year of university, I feel under-prepared to move outside my cultural comfort zone and uncertain how to teach music amidst cultural multiplicity (by this, I mean many cultures, broadly defined). I'm motivated by this disorienting dilemma to explore my own music teacher education.

In need of guidance,

The Student

\section{Researcher to Student}

Dear Student,

Thank you for writing and please know that you are not alone in feeling this way. Current thinking on preparing music teachers for cultural multiplicity emphasizes the inclusion of many musical materials and practices (Bond 2017, Carson and Westvall 2016, Hess 2018a), teaching diverse student populations (Bond 2017, Robinson 2016), and teaching about related concepts such as oppression and privilege (Bradley 2006, 2007; Hess 2018b; Westerlund and Karlsen 2017). I detect an unease within the literature on music teacher education, given that diversity coexists with structural inequity, divisive politics, multiple forms of oppression, and violence against those perceived as "different" (Hess 2018a, 25). Some unease stems from a concern that pre-service music teachers are not being equipped with the attitudes, dispositions, and skills (Robinson 2016) required for navigating "diverse diversities and rapid societal change" (Westerlund and Karlsen 2017, 95). Perhaps you have started to acknowledge the importance of who is taught what music, how, why, and by whom, but are unsure how to act upon that acknowledgment. I have asked a music educator to write to you about their experience, so you may find a way to proceed.

Regards,

The Researcher

\section{Music Educator to Student}

Dear Student,

These uncomfortable feelings you are experiencing can lead to meaningful change. Initially, I also felt ill-prepared for the cultural multiplicity in my teaching 
practice, and it was this feeling that guided me toward the concept of cultural humility. Already an established concept outside of music education, cultural humility refers to engaging humbly with those who are culturally different from oneself. Culture is broadly understood as including, but not limited to, ethnicity, race, gender, age, religion, sexuality, socioeconomic background, education, ability, health status, profession, parent/non-parent status, where you live, and language. ${ }^{6}$ Such a broad conceptualization recognizes that each individual is unique because of the intersectional, dynamic, and complex nature of culture.

One often-cited justification for education research on cultural humility is a demographic divide between teachers and students (e.g., Tinkler and Tinkler 2016). A similar divide in music education is a point of concern: pre-service teachers are predominantly White and middle-class, whereas student populations are increasingly diverse (Bond 2017, Hess 2017, 2018b, Kindall-Smith 2012, McKoy 2013, Robinson 2016). Multiple facets of my cultural identities, as well as being racially and socio-economically privileged, make me feel that I am on the side of the divide that should exercise cultural humility. I consider cultural humility as a bridge for crossing that divide-a bridge constructed by multiple disciplines to navigate cultural differences. The Scholartist will know more about these multiple disciplines and so will join our correspondence on cultural humility. A letter should arrive shortly!

Best wishes,

The Music Educator

\section{Scholartist to Student}

Dear Student,

I will start where the Music Educator left off. Can you imagine a rope bridge? I picture a narrow deck that sways in the wind and that may wobble slightly when walked on. Perhaps you imagine a bridge across a river or chasm, in a forest, or connecting the edges of a canyon or bluff. Using the bridge may feel uncomfortable or intimidating, especially if you are afraid of heights, as it shifts under each step. To cross that bridge, you need to be open to learning from both sides. Think of the two sides of the divide as different cultures and the rope bridge that connects them as cultural humility.

Cultural humility is an interesting concept to pursue, but we must engage with literature outside of music education to know more. American researchers in the 
field of medicine Tervalon and Murray-García (1998) originally coined the term cultural humility. Research on cultural humility within education is relatively minimal (Brown, Vesely, and Dallman 2016; Cervantes and Clark 2020; Lund and Lee 2015; Tinkler and Tinkler 2016; Vesely, Brown, and Mehta 2017) and emergent within music education (Conkling 2019, Dolloff 2020, Hess 2021). In contrast to education research, research on cultural humility within the health sciences and community services 7 has grown substantially over the past two decades.

From,

The Scholartist

\section{Student to Selves}

Dear All,

The term cultural humility may not be well established within music teacher education, but the idea of working with many cultures is. I've taken multiple ethnomusicology courses, and I've encountered the approaches of multiculturalism, culturally responsive education (Bond 2017), ${ }^{8}$ and cultural competence. Is yet another approach needed?

Yours truly,

The Student

\section{Researcher to Student}

Dear Student,

A good point. Ethnomusicology, which emphasizes "music in culture and music as culture" (Campbell 2004, 26, italics original), has a history of collaboration with music education (Campbell 2003). For example, ethnomusicologists have encouraged change in how music teachers are educated (Rice 2003, Schippers 2010) by promoting an expanded perception of ensemble, repertoire, and the social experience of music (Campbell and Higgins 2015). While I agree that the absence of cultural humility from music education literature does not necessarily justify its exploration, I think concerns about existing approaches create an opportunity to consider cultural humility. I will address some shortcomings of multiculturalism, culturally responsive education, and cultural competence.

Multiculturalism refers to the presence of many cultures and has been critiqued for restricting culture to race and ethnicity (Westerlund and Karlsen 2017), 
for not requiring interaction between cultures (Carson and Westvall 2016), and for failing to explicitly address systemic issues, such as racism (Hess 2017, Bradley 2006). Think of multicultural music education as a table surrounded by a variety of chairs. Although many chairs (i.e., cultures of music) may be included around the central table, they remain on the periphery. The chairs never attain the central status of the table, for they represent the "multi" to the dominant canon, often the White heteropatriarchy of Western classical music (Bradley 2007).

A much more individualized approach characterizes culturally responsive education, which focuses on who and how one teaches (Abril 2013) by recognizing, validating, and including each student's culture in education settings (Bond 2017). I am reminded of a spotlight: though a culturally responsive approach may illuminate aspects of a student's culture, the complex and dynamic nature of culture (Cain 2015) results in a great deal being left in the dark. For example, students may not wish to disclose elements of their cultural identities (e.g., socioeconomic background, sexuality) but would prefer to keep them out of the spotlight. A spotlight also shines one way and may reinscribe hierarchies. Specifically, the literature suggests that it is the teacher who responds to the cultural identities of students, with little indication of a reciprocal relationship whereby students also respond to the culture of the teacher. The teacher's spotlight only shines on those who are present. While it would be unrealistic for all cultural identities to be present in a music education setting and for a music educator to respond to all variations, teachers need more guidance in responding to absent cultural identities.

Finally, cultural competence is the most controversial of these approaches and is intensely criticized outside of music education (e.g., Fisher-Borne, Cain, and Martin 2015). Cultural competence refers to the ability to effectively function within the context of various cultural beliefs and behaviors while also affirming multiple cultural experiences, values, and knowledges of students (McKoy 2013). Critiques focus on competence, with its implication of an endpoint for learning and, therefore, a static view of culture (e.g., Bennett and Gates 2019), a potential for mastery over another's culture (e.g., Tervalon and Murray-García 1998), and a reliance on knowledge to gain comfort with difference rather than addressing systemic inequalities (e.g., Fisher-Borne, Cain, and Martin 2015). To use one final analogy, cultural competence reminds me of a futile search for the horizon. Though there may appear to be a reachable destination and perhaps even a straightforward 
path, no matter how much you learn about a culture, there is no endpoint for one to reach.

Regards,

The Researcher

\section{Scholartist to Selves}

Dear All,

Since you seem to gravitate toward cultural humility, I will suggest a definition of the concept. This is important considering the numerous definitions circulating. To name just a few, cultural humility represents a link between cultural diversity and social justice, a lens for framing advocacy, a filter through which to gain awareness of culture (Fisher 2020); an attitude, a stance, a discourse (Dolloff 2020); a goal, a way of being, a commitment, and a process (Tschaepe 2018). Although originally defined as a process (Tervalon and Murray-García 1998), much more has been said about the concept of cultural humility since it was first introduced.

To organize the vast and varied literature on cultural humility that exists across a range of disciplines, I draw on the work of psychology researchers, Joshua Hook and colleagues (2013), who conceptualize cultural humility (and humility generally) as having an intrapersonal and interpersonal dimension. These dimensions provide a means of bringing together diverse literature and offer a starting point for music education. Overall, my synthesis of the vast body of literature on cultural humility suggests that cultural humility is an ongoing process for thinking about and working, interacting, and living with cultural multiplicity, broadly defined. The intrapersonal dimension involves a process of self-reflection, awareness, and critique. The interpersonal dimension balances this inward-focus and includes the formation of respectful relationships and challenges to power imbalances through advocacy and activism. To meaningfully engage with cultural humility on an individual and institutional level requires a third dimension that bridges the intrapersonal and interpersonal dimensions. This bridging dimension encompasses openness and accountability. I have created a visual representation of these dimensions, as shown in Figure 1, using arrows to represent the processual, continuous, and multidirectional nature of cultural humility. This figure can guide our continued discussion.

From,

The Scholartist

Janes, Hayley. 2021. Cultural humility in music teacher education: A virtuous vice, a vicious virtue. Action, Criticism, and Theory for Music Education 20 (1): 84-120. https://doi.org/10.22176/act20.1.84 


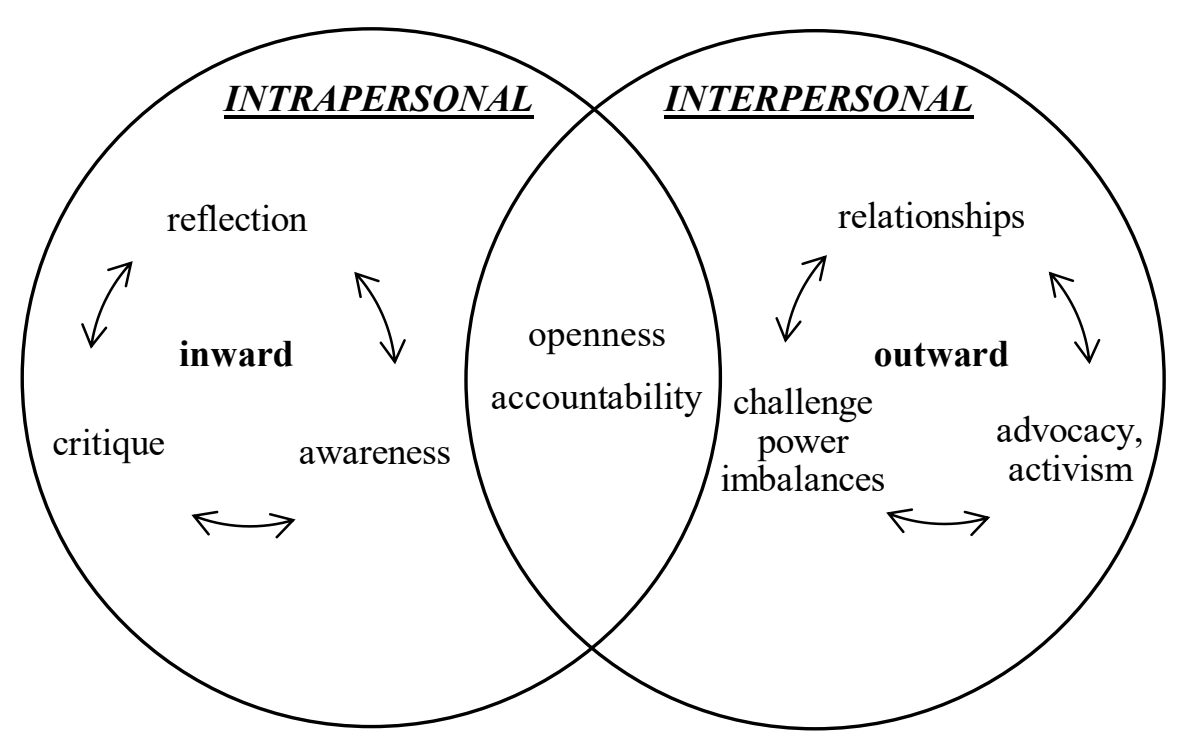

Figure 1 Tripartite model of cultural humility

\section{Researcher to Student}

Dear Student,

Do you have any examples relating to the intrapersonal dimension to supplement the Scholartist's discussion? I am curious about potential applications and implications of cultural humility on an individual and institutional level within music teacher education. The left of Figure 1 shows that the inward process of cultural humility involves engaging with the self through reflection, awareness, and critique (Bennett and Gates 2019, Lerner and Fulambarker 2018, Masters et al. 2019, Cervantes and Clark 2020). The intent is to surface and critically engage with personal biases, prejudices, assumptions, preconceptions, cultural conditioning, and worldview (Jisrawi and Arnold 2018). From this engagement comes an acknowledgment that any cultural worldview is limited, and there is an inability to understand the cultural identities and experiences of those who differ from oneself (Hook et al. 2013). Thoughts?

Regards, The Researcher 


\section{Student to Researcher}

Dear Researcher,

On an individual level, I'm reminded of one of my past assignments that involved writing about personal cultural identities. I wrote about my lack of culture because I was fully convinced that I was "culture-less"-narrowly thinking of culture as something possessed only by the exotic and ethnic "other," as something found elsewhere (Hess 2015). My whiteness, middle-class background, education, age, and cisgender female identity didn't figure into my self-description, nor did I interrogate the normative status of these identities and the privilege they afford me not to notice my culture. By engaging with the intrapersonal dimension of cultural humility, I now realize that my selves are largely absent from an assignment that was intended to be about me. At the time, I lacked the humility to confront my assumptions, biases, and prejudices about culture head-on. I can imagine music education students benefitting from the inward gaze of the intrapersonal dimension of cultural humility because it requires them to realize, reflect on, and ultimately critique the cultural identities everyone brings to any musical encounter.

The intrapersonal dimension is also relevant at an institutional level. Exercising cultural humility broadly in music teacher education could involve reflecting on which courses are mandatory and which are optional, where within the curriculum the challenge of looking inward does and does not happen, and what message this sends. In my music teacher education, mandatory courses on Western classical music are content-based (e.g., memorizing music history and theory terms) and skills-based (e.g., learning to conduct beat patterns and symphonic repertoire). Matters of oppression, privilege, systemic inequalities, and the resulting "isms" are included predominantly in elective courses that explicitly focus on "non-Western" material and practices. Discussing these important issues in optional courses sends the message that these are optional discussions. Within these elective courses, I challenge the content and mandatory status of Western classical music courses. This not only suggests that such engagement is optional, but that such challenges are not required to come from within Western classical music. I liken this to my lack of humility when writing about personal cultural identities and assumptions. From auditioning for the program to meeting the requirements to graduate, dead White men serve as gatekeepers. Perhaps one such implication of 
cultural humility in music teacher education is the removal of these gatekeepers from their posts.

Yours truly,

The Student

\section{Researcher to Music Educator}

Dear Music Educator,

The student wrote to me with their thoughts regarding the intrapersonal dimension of cultural humility. Do you have any examples relating to the interpersonal dimension, individually and broadly speaking? On the right of Figure 1, the interpersonal dimension is characterized by an outward focus and willingness to engage with multiple cultures (Brown, Vesely, and Dallman 2016).

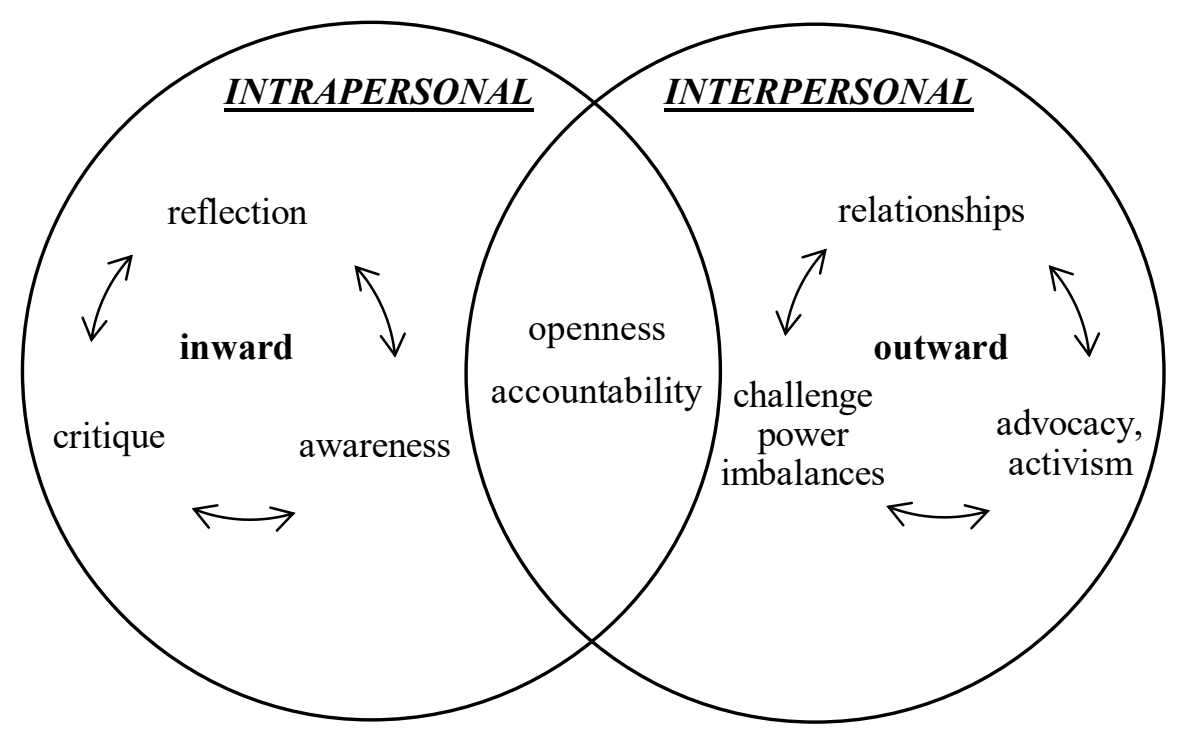

Meaningful and mutually beneficial relationships are central (Tervalon and Murray-García 1998). These relationships honour individuals as the expert of their lived experiences (Tormala et al. 2018) while also allowing them to decide what cultural identities are relevant and how much bearing they have in various situations (Tervalon and Murray-García 1998). Interactions occur between individuals, not cultures (Hurley, Kostelecky, and Townsend 2019), and so no person should be expected to be a spokesperson for their culture (Bennett and Gates 2019). Advocacy and activism support these relationships (Masters et al. 2019) and extend into practice and policy to mitigate power imbalances (Keselman and Awais 2018) and challenge the "structural forces and social, political, and historical contexts 
that serve to marginalize and oppress communities, not just individuals" (Abe $2019,3)$. Overall, the outward focus of the interpersonal dimension balances the more inward focus of the intrapersonal dimension.

Regards,

The Researcher

\section{Music Educator to Researcher}

Dear Researcher,

Some questions came to mind when I read your letter: who did my music education program prepare me to work with? Who was I unprepared to work with? Whose music was I taught to teach to whom, and how? I experienced an inner conflict near the end of my music teacher education. After being immersed in Western classical music for years, I couldn't help but feel a sense of pride over my growing knowledge of this genre. At the same time, I was experiencing an overwhelming sense of inadequacy when teaching violin at a local studio. I found myself faced with neurodiverse students, differently abled students, students from a range of socioeconomic backgrounds, students with varied family structures, students of diverse gender identities and expressions, and students from disparate and mixed ethnic and racial backgrounds. I relied on the familiar and taught them all "Twinkle, Twinkle" and Bach minuets, at a loss for how to relate to such a diverse group of students. When I began to incorporate the interpersonal focus of cultural humility into my practice, I realized that my inability to relate directly to the cultures of my students should not affect my ability to form meaningful relationships with each individual that could guide my teaching.

In response to your question about the interpersonal dimension on a broader level, I believe that cultural humility is not restricted to immediate encounters with students. Music teacher education can become a space to consider how music education as a discipline promotes and hinders the meaningful, respectful, mutually beneficial, and non-paternalistic relationships central to cultural humility (Tervalon and Murray-García 1998). For example, how might music education foster relationships that emphasize the importance of the human connection (Niknafs 2020)? How can these relationships become a force for advocacy and activism (Hess 2019) to challenge power imbalances? Equally important is acknowledging and confronting shortcomings. This would involve continually questioning what more music educators can (and must) do to dismantle systems of inequality, 
oppression, discrimination, violence, and hate. It comes down to this: cultural humility requires a lifelong commitment (Tervalon and Murray-García 1998). The point at which you believe you are culturally humble is the moment at which cultural humility is most needed. Similarly, we can always do more within music education to improve the way we work, live, and interact with the multiplicity of dynamic cultures that exist.

Best wishes,

The Music Educator

\section{Researcher to Music Educator and Student}

Dear Music Educator and Student,

I appreciate your examples: critiquing personal assumptions, fostering meaningful and mutually beneficial relationships, and confronting disciplinary shortcomings. I also question what one may need to accomplish what you have suggested. Let me draw your attention to the middle of Figure 1, where the placement of openness and accountability emphasizes their applicability to both the intrapersonal and interpersonal dimensions. This is a significant expansion on the intrapersonal and interpersonal binary because it connects the two dimensions while also clarifying the need for openness and accountability in order to engage in the process of cultural humility on an individual and institutional level.

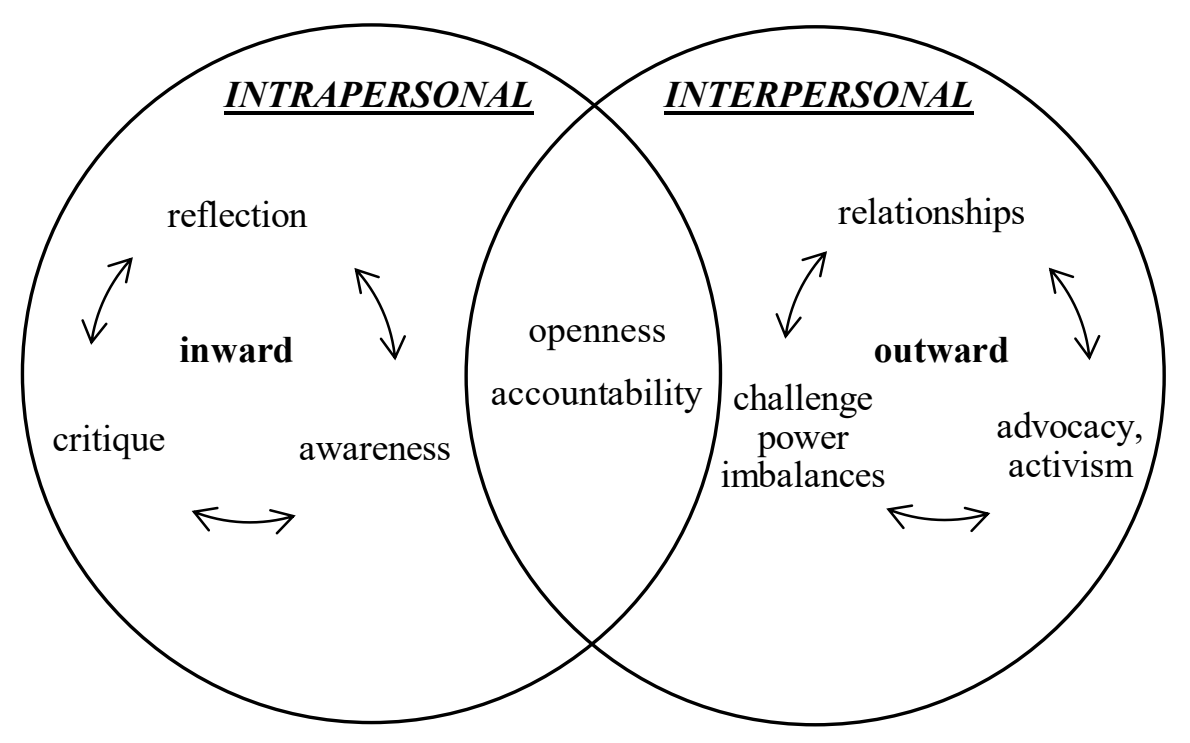

Janes, Hayley. 2021. Cultural humility in music teacher education: A virtuous vice, a vicious virtue. Action, Criticism, and Theory for Music Education 20 (1): 84-120. https://doi.org/10.22176/act20.1.84 
An open stance helps avoid stereotyping and essentializing cultures and is foundational to cultural humility (Hurley, Kostelecky, and Townsend 2019). Instead of anticipating what a cultural interaction might be like, proponents of cultural humility advocate for openness toward self-reflection, awareness, critique, and the limitations of one's worldview (Hook et al. 2013); new ideas (Foronda et al. 2016); interacting with someone culturally different from oneself (Tschaepe 2018); the resources that exist as a source of strength within communities (Tervalon and Murray-García 1998); and the multiple understandings of and experiences with cultural diversity that exist (Lund and Lee 2015).

Finally, exercising cultural humility requires action-oriented accountability to engage in these intrapersonal and interpersonal processes on an individual and institutional level (Fisher-Borne, Cain, and Martin 2015). What has been your experience around openness and accountability in music teacher education, and how might they be applied institutionally?

Regards,

The Researcher

\section{Student to Researcher and Music Educator}

Dear Researcher and Music Educator,

My music teacher education has opened my ears and mind to new ideas and many musical cultures. I've learned about the resilience of Indigenous peoples of Canada through their musical practices, the artistry of Ghanaian styles of drumming and dance through study and performance, and the politicization of rock music in Iran through the sharing of stories. Not only have I learned about madrigals, concertos, Monteverdi, Schumann, the Renaissance, and the French Revolution but also about plunderphonics, musical theatre, Jimi Hendrix, Tanya Tagaq, Neoshamanism, and the refugee crisis. I have written essays on Tuvan throat singing, Taiko drumming, the Truth and Reconciliation Commission of Canada (2015), Ewe drumming, and the Apache girls' puberty ceremony. However, I think the question is not only if musical multiplicity is included, but how. Most of these topics were in elective courses, whereas I studied madrigals, concertos, Monteverdi, Schumann, the Renaissance, and the French Revolution in mandatory courses. Additionally, the focus remained outward on learning about these topics rather than learning from direct experience. In contrast, I am required to play in an orchestra 
for the duration of the program. I feel a sense of openness and yet, I still feel illprepared to teach anything besides Western classical violin.

Yours truly,

The Student

\section{Music Educator to Student and Researcher}

Dear Student and Researcher,

I can relate to your experience, Student. When I graduated, I felt an openness toward new ideas, multiple cultures, and learning from each musical interaction, but it wasn't enough. I was uncertain about my accountability as an individual music educator. It was a simple, yet pestering question: now what? I continue to find guidance in the words of social work scholar, Jennifer Abe (2019):

Cultural humility requires a cultural decentering and acknowledgment of oppression and power as our gaze shifts from our own perceptions of the world to see, instead, the reality of the other. And this gaze is not indifferent but instead regards the other in all her dignity and intrinsic value, with respect, openness, and a willingness to learn and to be changed (8).

In exercising cultural humility, I entwine accountability and openness. I'm accountable as an individual to remain open to the intrapersonal dimension, so I may continually remind myself that my perspective of the (musical) world is just that, one perspective among many (not all of which are treated equally). Engaging in the interpersonal dimension also requires openness and accountability; it involves decentering myself by moving away from my perspective and toward the larger structural forces that uphold multiple systems of oppression and require a collective effort to dismantle.

To your question, Researcher, about openness and accountability on an institutional level: I see this as cultural humility applied to the very idea of music education. Nasim Niknafs (2018) suggests that music education can be interpreted as a "cultural arena where questions of creativity, artistry, resourcefulness, legitimacy, circulation, consumption, and affectivity come to the fore" (158). To apply cultural humility to music education might involve institutions (and individuals) entering that "cultural arena" with an openness toward diverse narratives of music education and accountability to engage in them. Entering that arena from a position of cultural humility would require a "cultural decentering" (Abe 2019, 8) in order to "dismantle the implied assumptions that good music education should 
take forms recognizable to Euro-American sensitivities" (Niknafs 2018, 171). Engaging with challenging questions 9 is a place to start, such as whether the institutional ethos supports inclusion and respectful, substantive discussions of the musical implications of difference (Tervalon and Murray-García 1998, 122). However, most important is the accountability of institutions to act (Fisher-Borne, Cain, and Martin 2015), for "words matter and words have influence, but words do not, by themselves, magically create change" (Danso 2018, 421). Perhaps committing to the process of cultural humility could drive that change for music teacher education.

Best wishes, The Music Educator

\section{Problematizing Cultural Humility}

\section{Student to Scholartist}

Dear Scholartist,

I've been corresponding with the Music Educator and Researcher about your figure on cultural humility. The inward and outward focus, plus the emphasis on openness with accountability all sound wonderful, but I think that's the very problem. I had the opportunity recently to substitute teach for a community music program in a "vulnerable" part of the city. It seemed like an ideal opportunity for me, a White classical violinist, to enact cultural humility in practice. It didn't go wonderfully...

My hair was fuzzy. I felt sticky sitting on the bus while the rain pattered against the window; I was wearing too many layers under my raincoat, and I felt nauseous, too, from the stop and go of the bus and the musty rain smell. Perhaps it was nerves over what to expect. I clenched my violin case between my knees and unclenched my jaw; I was definitely nervous. There was still a way to go, and so as the bus bumped along, I tried to reflect on my assumptions, shortcomings, and cultural background to get to the root of these nerves. The realization that most of my teaching experience comprised teaching violin lessons to White students whose families could afford private lessons and wanted their children to learn classical violin had me feeling under-prepared (which I can't stand, as you might recall). Too bad I had learned about hexachordal combinatoriality rather than how to teach music in a vulnerable community to students with vastly different cultural 
backgrounds from my own. The bus stopped, and I stepped off, case slung over my shoulder, umbrella up. I felt that I was musically and culturally out of my element. While I walked toward the entrance of the school, I tried to focus my thoughts on being open to this new teaching experience, staying aware of my assumptions, and trying to foster relationships with the students. Cultural humility was my lifeline.

I wandered through the halls until I found a teacher who gave me a rundown of how things worked. Then it was just me and the students. They were a welcoming group of about twenty children, many of whom were Black, Brown, newcomers to Canada, and/or from low-income families. The first challenge for my White ears were the names of the students. I needed to learn these names correctly if I were to have a respectful relationship with these students, and so we played a game where each student introduced themselves. For the warmup activity, we played a movement game using songs the students requested. After a chorus of "that was fun!" it was time for the next activity which, according to lesson ideas that the teacher had left for me, was playing Orff instruments. I was trying to stay open to what these students were interested in, and so I thought I was acting from a place of cultural humility when I decided against having these students play Orff instruments. Surely xylophones, metallophones, and glockenspiels weren't "relevant." The students were excited to show me their music theory knowledge, and so we continued the lessons on reading notation and counting quarter notes.

When it came time to wrap up the class, I realized that I was operating on another assumption: it was problematic that the purpose of this introductory program was to prepare these students to eventually learn violin. Having caught myself in that moment, I shifted to a place of humility to try to gauge how these students felt about the program. When I took out my violin and asked if they wanted me to play for the final movement game, they were bursting with excitement. These students really wanted to play violin.

While sitting on the bus heading home, I reflected on the mixed feelings I had about the experience. Knowing about cultural humility had helped me accept this position when it was offered, but I felt bad about all the assumptions I had made. I realized I had been nervous because I had assumed that these children would be challenging to work with, given the community in which they lived. I had also been nervous to teach students who were different from me, both culturally and musically. Although I had tried to enact tenets of cultural humility such as being selfreflective and open toward the musical interests and strengths of these students, I 
had also assumed that cultural humility would transform my teaching and make challenges easier. I'm now left with the impression that I'm missing something about cultural humility, something that would explain why cultural humility didn't help me teach in the very context it's intended to be of use.

In need of guidance once again,

The Student

\section{Music Educator to Student}

Dear Student,

Please excuse my interjection. I thought I might provide my insight about your experience before the Scholartist goes deeper with cultural humility. Your account included different types of assumptions-those of which cultural humility made you aware and those that you had about cultural humility itself. You reflected on and were aware of assumptions you were making while on the bus, while teaching, and while heading home. Critique, a tenet of the intrapersonal dimension, can help push reflection and awareness further. For example, your attempt at using cultural humility in connection with the Orff instruments revealed another assumption to be interrogated: that Orff instruments are not relevant to this demographic of students.

There are also some assumptions you made about cultural humility that may have contributed to your impression that the concept did not help you teach in this context. Though I appreciate your attempt to use cultural humility, you also assumed that just knowing about cultural humility leads to change. Cultural humility needs to be practiced, and this takes time and experience. Remember, cultural humility is a process, and it is a process that happens on an individual and institutional level. I noticed that you underestimated the importance of institutional support to foster the development and practice of cultural humility. Such support is important to enact the interpersonal dimension. Perhaps your experience would have been different if your music teacher education had included cultural humility.

The next assumption about cultural humility is one that you identified: that it sounds wonderful and would transform your teaching by making challenges easier. In other words, you assumed that cultural humility is "all good." Our letters to date may have contributed to this perspective and may have also given the impression 
that cultural humility can easily transfer to music education. Perhaps the Scholartist can address these shortcomings and explore what is missing or rather, going unnoticed within the concept of cultural humility.

Best wishes,

The Music Educator

\section{Scholartist to Student}

Dear Student,

The Music Educator is correct. There is an element of cultural humility we have yet to explore. Literature across disciplines is overwhelmingly positive toward cultural humility, though some concerns have been raised, such as its time-intensive and financially costly training (Sprik and Gentile 2020) or its lack of originality (Danso 2018). Humility's reputation as a virtue, a socially valued attribute (Weidman, Cheng, and Tracy 2018) that makes one more admirable (Murphy 2017) is largely responsible. Various religions ${ }^{10}$ and the positive psychology movement uphold this reputation, which has implications for the concept of cultural humility. Specifically, social work scholar Ransford Danso (2018) argues that research relies on the semantic appeal of cultural humility. Just the sound of the concept is appealing to people, and I have gotten positive responses when just mentioning cultural humility without having to provide any further explanation.

I am unsettled and reminded of a warning from Sara Ahmed (2012), that "solutions to problems can create new problems" (46). I turn now to literature from philosophy and psychology, for humility is a complicated concept that "cries out for interdisciplinary inquiry" (Murphy 2017, 19). A problematization of humility and its virtuous reputation is necessary to explore what is going unnoticed within the concept of cultural humility.

To start, there is the theory that humility is a cluster virtue (Murphy 2017)that it is at the core of a group of virtues such as love, compassion, forgiveness, altruism, generosity, gratitude, and empathy, which all require humility's otherorientedness (Worthington, Davis, and Hook 2017). If cultural humility is similarly a cluster virtue, then perhaps exercising cultural humility requires more than just humility. Pride could even be present. Psychology and neuroscience researcher Michael Spezio, along with philosophers Gregory Peterson and Robert Roberts (2018), define humility as the intentional absence of the vices of pride, not pride itself. Pride can coexist with humility so long as it does not deteriorate to an 
"unrestrained inflation" (Spezio, Peterson, and Roberts 2018, 3) of the value of the self and associated groups. Such unrestrained inflation results in the vices of pride, which include grandiosity, domination, hyper-autonomy, arrogance, vanity, snobbery, and envy (Spezio, Peterson, and Roberts 2018). Though Spezio and colleagues (2018) are not writing specifically about cultural humility, they list some vices of pride that could be considered vices of cultural pride. The deterioration of cultural pride could result in vices such as "racism, sexism, ethnic hatred, religious hatred, and homophobia" (Spezio, Peterson, and Roberts 2018, 3). Cultural humility could thus coexist with cultural pride but would require the intentional absence of the vices of cultural pride that result from unrestrained inflation of the self and associated groups.

I am still troubled by your fundamental assumption that cultural humility is "all good," as pointed out by the Music Educator. The problem with both the cluster virtue theory and the theory that humility is the intentional absence of the vices of pride is that they support dichotomous thinking. Whether cultural humility is a cluster virtue and/or is the absence of the vices of cultural pride, we are limited to thinking that having cultural humility is "good" and not having it is "bad." An inability to interrogate our assumptions about cultural humility using these theories leads me to consider if there is a negative side to humility. Even if the vices of cultural pride are absent when exercising cultural humility (e.g., absence of homophobia), perhaps vices of cultural humility can be present.

Psychologist Aaron Weidman and colleagues (2018) explored the "dark side" of humility through a bottom-up analysis of the psychological structure of humility, which incorporated theological and philosophical perspectives and popular opinion. Their findings suggest that humility can take either an appreciative (positive) form or a self-abasing form involving negative self-evaluation, shame, low self-esteem, and submissiveness. Cultural humility could take a self-abasing form and bring up feelings of self-deprecation, which might explain why you felt "bad" about the assumptions you made rather than appreciating the attempt and the learning that came from the teaching experience.

I am still not satisfied. Recall Figure 1 from our previous correspondence, which presented cultural humility as having an intrapersonal, interpersonal, and bridging dimension. Restricting the negative side of cultural humility to forms of self-deprecation only addresses the intrapersonal dimension because the focus remains on the self. What if cultural humility is vicious overall? "Vicious" derives from the Latin word vitiōsus which means faulty, defective, corrupt, and/or wicked 
(Morwood 2005). In other words, is cultural humility full of vice? Is cultural humility a faulty virtue? Might there be positive and negative implications of cultural humility on an intrapersonal and interpersonal level?

From,

\section{The Scholartist}

\section{Researcher to Scholartist}

Dear Scholartist,

I am inspired by your suggestion that cultural humility might be vicious and full of faults. I have come up with some questions in response to the Music Educator's suggestion that cultural humility cannot simply transfer into a music education context. These are important questions to consider should cultural humility be brought into music teacher education:

1. Should you be culturally humble toward all cultures (e.g., all musics)? If so, why? If not, why not? How is this decided and by whom?

2. Who should be culturally humble (e.g., within music teacher education) and how does this relate to power, positionality, and privilege? I heard a phrase once, only the powerful can be merciful. Like the virtue of mercy, is having power and privilege a precondition for practicing cultural humility? Does the practice of cultural humility further perpetuate that positioning?

3. Does the meaning and experience of cultural humility change depending on who is interacting?

To take these questions into account requires a shift in perspective. In contrast to the existing humility cluster theory, I take the slightly different view that cultural humility is not itself a cluster of virtues but is possessive of a cluster of virtues and also a cluster of vices. Thus, cultural humility is not itself a virtue or vice but has both virtues and vices. This subtle, yet important shift, results in a more nuanced approach to cultural humility. Depending on the context, cultural humility may have positive virtuous implications, negative vicious implications, or a combination.

Regards,

The Researcher 


\section{Scholartist to Researcher}

Dear Researcher,

These positive implications to which you refer might include acceptance, empathy (Jisrawi and Arnold 2018); acknowledging limitations, an approach of openness and respect, transformation (Lerner and Fulambarker 2018); being egoless (Foronda et al. 2016); improved relationships (Bal and Kaur 2018); and the absence of the vices of cultural pride.

I will focus in more detail on some potentially vicious implications. In connection with your first question (should you be culturally humble toward all cultures?), there is a risk of broadly applying cultural humility and remaining open to and accepting of cultural practices that could be harmful and in need of change (e.g., symphony orchestra conductors being predominately male). The challenge is knowing when and when not to be culturally humble and how to make that decision. Perhaps cultural humility requires some knowledge of the context. For example, I cannot say I am humble in the context of aerospace engineering because I know absolutely nothing about the discipline. Remaining completely open with no knowledge of the culture and the particular context could characterize a form of ignorance. If such ignorance is mistaken for cultural humility, cultural humility becomes vicious, in that specific contexts are not considered, and problematic practices go unaddressed.

Questions 2 (who should be culturally humble?) and 3 (does the meaning and experience of cultural humility change depending on who is interacting?) emphasize the implications of who is practicing cultural humility. If only those in positions of power and privilege practice cultural humility, then the very things cultural humility may mitigate (i.e., privilege and power imbalances) become a pre-requisite for practicing cultural humility. Thus, one of the potential vices of cultural humility is that it becomes an exclusive practice for the elite. This may be a shortterm vice, however. If understood instead as an iterative and transformative process, then continually practicing cultural humility may lead to a gradual reduction of hierarchy. Striking the balance between decentering yourself (i.e., interpersonal dimension) and recentering yourself (i.e., intrapersonal dimension) is critical to this process.

From,

The Scholartist 


\section{Researcher to Scholartist}

Dear Scholartist,

An additional problem arises if everyone is intended to exercise cultural humility. Sarah Kostelecky and Lori Townsend, two Indigenous library-studies researchers in the United States, pose the question: "does cultural humility ask us to hide our light, our strength, and our beauty so that members of the dominant culture can feel more comfortable?" (Hurley, Kostelecky, and Townsend 2019, 552). Their question expands on Danso's (2018) argument that cultural humility is semantically appealing by suggesting that it can also be "semantically appalling to people of color and others who have been required to humble themselves, in the most negative sense before the dominant culture" (Hurley, Kostelecky, and Townsend 2019, 552, italics original). Psychology researchers Sarah Moon and Steven Sandage (2019) further argue that the language and practice of cultural humility must be differentiated for therapists of color to account for the "traumatic effects of racism, microaggression, intergenerational trauma, and the pressures to assimilate to White culture" (78). For therapists of color (and music educators of color), self-denial, questioning, doubt, and minimization may be mistaken for displays of cultural humility when they are, in fact, an internalization of racism (Moon and Sandage 2019). In your previous correspondence with the Student, you suggested that cultural humility can coexist with cultural pride. Supporting the coexistence of cultural humility and cultural pride is important if music teacher education is to mitigate the vicious potential of cultural humility as a semantically appalling term, which would reinforce rather than change the status quo.

Regards,

The Researcher

\section{Music Educator to Researcher and Scholartist}

Dear Researcher and Scholartist,

I am still drawn to the process of cultural humility. At the same time, your correspondence helps me appreciate the concern that "cultural humility will be dismissed, or accepted, without thoughtful consideration, merely because it is seen as trendy" (Hurley, Kostelecky, and Townsend 2019, 552). Your thoughtful consideration presents cultural humility as a virtuous vice and a vicious virtue-virtuous in the sense that exercising cultural humility in music teacher education has potential on an intrapersonal and an interpersonal level, whether it is to provide 
guidance for confronting personal assumptions or to require institutional accountability for action. However, a vicious cycle emerges when that potential is not realized; cultural humility instead becomes semantically empty or non-performative because it does not produce the effects it names (Ahmed 2012). Such a cycle could see the language of cultural humility appropriated by those looking to feel better about themselves rather than acting for concrete change. Addressing the range of implications of cultural humility is an important first step for music teacher education. This requires considering the context of interactions, allowing for multiple permutations of cultural humility that can coexist with cultural pride, and adopting a more nuanced understanding of humility that goes beyond just a virtue or form of self-abasement.

Best wishes,

The Music Educator

\section{Student to Selves}

Dear All,

Wait a minute! I think I'm starting to understand this process of proposing and problematizing. Maybe our correspondence has also been full of faults. After all, who has the "response-ability" (Mackinlay 2016, 68) to define humility in the context of cultural humility? Isn't humility itself a cultural term? For example, Indigenous scholar Kathleen Absolon (2016) highlights the importance of humility as one of the seven sacred teachings of the Anishinaabe First Nations people. Those who exercise cultural humility define and understand cultures within individual contexts rather than rely on static definitions (Tervalon and Murray-García 1998). Considering the cultural nature of humility, shouldn't we take the same contextual approach when conceptualizing cultural humility? I feel that we've limited ourselves to Western-based philosophical, religious, and psychological thinking by using the terms virtues and vices. I've learned that humility involves constant considerations and a comfort with never knowing rather than satisfying conclusions. Never knowing means reflecting, redefining, rethinking, and always returning to the basic question, what is cultural humility? And so, let us begin again...

Yours truly,

The Student 


\section{After Words Comes Parting Thoughts}

\section{Dear Reader,}

These letters are just the beginning of my (our) journey with cultural humility. Through the reflective, dialogic, interactive, and connective practice of letter writing, I have made connections between my experiences, my thoughts, wider theories, and wider contexts. Overall, using a critical autoethnographic epistolary has brought importance to both what and how I want to communicate about cultural humility.

American music education scholar, Nicole Robinson (2016), argues that the field of music education has acknowledged the need for more diversity preparation but not how best to prepare pre-service teachers for that diversity. Shortcomings of multiculturalism, culturally responsive education, and cultural competence create an opportunity to consider cultural humility. At the same time, "culture is too slippery and untamable a phenomenon for any single framework, however all-embracing, to be able to fully capture or analyze its complex permutations and manifestations" (Danso 2018, 419). Perhaps music teacher education needs a combination of approaches that could draw upon the "slippery" and complicated nature of cultural humility. I have offered a proposal and problematization for music education, raising points about cultural humility for educators to consider. By organizing the literature on cultural humility into intrapersonal and interpersonal dimensions (Hook et al. 2013) and a third bridging dimension, I have proposed a framework to use as a starting point for music educators. My problematization of cultural humility led to the suggestion that the concept is virtuous and vicious, a suggestion interrupted by a last letter from the Student. This letter ended with an open invitation to begin again, a reminder that cultural humility is not a "one-sizefits-all" solution or any "solution" for that matter.

Additional research on cultural humility that explores the perspectives of music teacher educators will further contribute to (and complicate) the conversation. Invoking the concept of cultural humility with students needs further investigation. For example, what does cultural humility mean in a high school music program or an early childhood music class at the local community center? What does it mean to develop cultural humility through the arts, through music? Are the arts and music well suited for this purpose, and if so, how or if not, why not? How might one interpret cultural humility through more specific theoretical lenses (e.g., feminist, queer, decolonial) rather than the broad critical social theory lens I adopted 
for this epistolary? Finally, the practical side of cultural humility regarding pedagogy and curriculum within music teacher education needs to be explored, in order to optimize positive implications and mitigate negative implications.

I write to you, Reader, at a time when music teacher education functions in a world teetering on a threshold, balancing precariously amidst a pandemic, a climate crisis, and a wave of protests against anti-Black racism and police brutality. I see this threshold as an opening and opportunity for transformation. If cultural humility is to have a role in moving music teacher education through that opening, then we must address the concept's range of implications so it can withstand the challenges posed by our complicated, messy, and unequal world.

Sincerely,

The author

\section{About the Author}

Hayley Janes is a PhD student in Music Education at the University of Toronto. She holds an MPhil in Arts, Creativity, and Education from the University of Cambridge. Hayley has taught violin in community and studio-based programs in Toronto. Her research interests include cross-cultural education philosophies, artsbased research methodologies, and higher music education.

\section{References}

Abe, Jennifer. 2019. Beyond cultural competence, toward social transformation: Liberation psychologies and the practice of cultural humility. Journal of Social Work Education 56 (11): 1-12. https://doi.org/10.1080/10437797.2019. 1661911

Abril, Carlos R. 2013. Toward a more culturally responsive general music classroom. General Music Today 27 (1): 6-11. https://doi.org/10.1177/104837 1313478946

Absolon, Kathleen E. 2016. Wholistic and ethical: Social inclusion with Indigenous peoples. Social Inclusion 4 (1): 44-56. https://doi.org/10.17645/si.v4i1.444

Adams, Tony E. 2017. Critical autoethnography, education, and a call for forgiveness. International Journal of Multicultural Education 19 (1): 79-88. https://doi.org/10.18251/ijme.v19i1.1387 
Adams, Tony E., Stacy Holman Jones, and Carolyn Ellis. 2015. Autoethnography: Understanding qualitative research. New York, NY: Oxford University Press.

Ahmed, Sara. 2012. On being included: Racism and diversity in institutional life. Durham, North Carolina: Duke University Press.

Anderson, Leon, and Bonnie Glass-Coffin. 2013. I learn by going: Autoethnographic modes of inquiry. In Handbook of autoethnography, edited by Stacy Holman Jones, Tony E. Adams, and Carolyn Ellis, 57-83. New York, NY: Routledge.

Bal, Jaspreet, and Rapinder Kaur. 2018. Cultural humility in art therapy and child and youth care: Reflections on practice by Sikh women (L'humilité culturelle en art-thérapie et les soins aux enfants et aux jeunes: Réflexions sur la pratique de femmes Sikhes). Canadian Art Therapy Association Journal 31 (1): 6-13. https://doi.org/10.1080/08322473.2018.1454096

Bennett, Bindi, and Trevor G. Gates. 2019. Teaching cultural humility for social workers serving LGBTQI Aboriginal communities in Australia. Social Work Education, 1-14. https://doi.org/10.1080/02615479.2019.1588872

Bond, Vanessa L. 2017. Culturally responsive education in music education: A literature review. Contributions to Music Education 42: 153-80.

Boylorn, Robin M., and Mark P. Orbe. 2014. Introduction: Critical autoethnography as method of choice. In Critical autoethnography: Intersecting cultural identities in everyday life, edited by Robin M. Boylorn and Mark P. Orbe, 1326. Walnut Creek, CA: Left Coast Press, Inc.

Bradley, Deborah. 2006. Music education, multiculturalism, and anti-racism: Can we talk? Action, Criticism, and Theory for Music Education 5 (2): 2-30.

Bradley, Deborah. 2007. The sounds of silence: Talking race in music education. Action, Criticism, and Theory for Music Education 6 (4): 132-62. http://act.maydaygroup.org/articles/Bradley6_4.pdf

Bray, Joe. 2003. The epistolary novel: Representations of consciousness. London, UK: Routledge.

Brown, Elizabeth L., Colleen K. Vesely, and Laura Dallman. 2016. Unpacking biases: Developing cultural humility in early childhood and elementary teacher candidates. Teacher Educators' Journal 9: 75-96.

Butler, Judith. 2005. Giving an account of oneself. New York, NY: Fordham University Press. 
Cahnmann-Taylor, Melisa, and Richard Siegesmund. 2018. Introduction. In Artsbased research in education: Foundations for practice, edited by Melisa Cahnmann-Taylor and Richard Siegesmund, 2nd ed., 1-11. New York, NY: Routledge.

Cain, Melissa. 2015. Musics of 'the other': Creating musical identities and overcoming cultural boundaries in Australian music education. British Journal of Music Education 32 (1): 71-86. https://doi.org/10.1017/So265051714000394

Campbell, Patricia S. 2003. Ethnomusicology and music education: Crossroads for knowing music, education, and culture. Research Studies in Music Education 21 (1): 16-30. https://doi.org/10.1177/1321103Х030210010201

Campbell, Patricia S. 2004. Teaching music globally: Experiencing music, expressing culture. Oxford: Oxford University Press.

Campbell, Patricia S., and Lee Higgins. 2015. Intersections between ethnomusicology, music education, and community music. In The Oxford handbook of applied ethnomusicology, edited by Svanibor Pettan and Jeff Todd Titon. New York, NY: Oxford University Press.

Carson, Charles, and Maria Westvall. 2016. Intercultural approaches and 'diversified normality' in music teacher education: Reflections from two angles. Action, Criticism, and Theory for Music Education 15 (3): 37-52.

Cervantes, Carlos M., and Langston Clark. 2020. Cultural humility in physical education teacher education: A missing piece in developing a new generation of socially just physical education teachers. Quest 72 (1): 57-71. https://doi.org/ 10.1080/00336297.2019.1608267

Conkling, Susan Wharton. 2019. Choral music education: Whence transformation? In The Oxford handbook of preservice music teacher education in the United States, edited by Colleen Conway, Kristen Pellegrino, Ann Marie Stanley, and Chad West, 719-47. New York, NY: Oxford University Press.

Danso, Ransford. 2018. Cultural competence and cultural humility: A critical reflection on key cultural diversity concepts. Journal of Social Work 18 (4): 410430. https://doi.org/10.1177/1468017316654341

Dolloff, Lori-Anne. 2020. To honor and inform: Addressing cultural humility in intercultural music teacher education in Canada. In Visions for intercultural music teacher education, edited by Heidi Westerlund, Sidsel Karlsen, and Heidi Partti, 135-48. New York, NY: Springer International Publishing.

Eisner, Elliot. 2008. Art and knowledge. In Handbook of the arts in qualitative research: Perspectives, methodologies, examples, and issues, edited by J. Gary Knowles and Ardra L. Cole, 3-12. California: Sage Publication, Inc. 
Ellis, Carolyn. 2000. Creating criteria: An ethnographic short story. Qualitative Inquiry 6 (2): 273-77. https://doi.org/10.1177/107780040000600210

Ellis, Carolyn, Tony E Adams, and Arthur P Bochner. 2011. Autoethnography: An overview. Historical Social Research 36 (4): 273-90. https://www.jstor.org /stable/23032294

Ellis, Carolyn, and Arthur P Bochner. 2006. Analyzing analytic autoethnography: An autopsy. Journal of Contemporary Ethnography 35 (4): 429-49. https://doi.org/10.1177/0891241606286979

Fisher, Emily S. 2020. Cultural humility as a form of social justice: Promising practices for global school psychology training. School Psychology International 41 (1): 53-66. https://doi.org/10.1177/0143034319893097

Fisher-Borne, Marcie, Jessie Montana Cain, and Suzanne L. Martin. 2015. From mastery to accountability: Cultural humility as an alternative to cultural competence. Social Work Education 34 (2): 165-81. https://doi.org/10.108o/ 02615479.2014.977244

Foronda, Cynthia. 2020. A theory of cultural humility. Journal of Transcultural Nursing 31 (1): 7-12. https://doi.org/10.1177/1043659619875184

Foronda, Cynthia, Diana-Lyn Baptiste, Maren M. Reinholdt, and Kevin Ousman. 2016. Cultural humility: A concept analysis. Journal of Transcultural Nursing 27 (3): 210-17. https://doi.org/10.1177/1043659615592677

Gouzouasis, Peter, and Jee Yeon Ryu. 2015. A pedagogical tale from the piano studio: Autoethnography in early childhood music education research. Music Education Research 17 (4): 397-420. https://doi.org/10.1080/14613808.2014. 972924

Held, Mirjam B. E. 2019. Decolonizing research paradigms in the context of settler colonialism: An unsettling, mutual, and collaborative effort. International Journal of Qualitative Methods 18: 1-16. https://doi.org/10.1177/ 1609406918821574

Hess, Juliet. 2015. Decolonizing music education: Moving beyond tokenism. International Journal of Music Education 33 (3): 336-47. https://doi.org/ 10.1177/0255761415581283

Hess, Juliet. 2017. Equity and music education: Euphemisms, terminal naivety, and whiteness. Action, Criticism, and Theory for Music Education 16 (3): 1547. https://doi.org/10.22176/act16.3.15

Hess, Juliet. 2018a. A “discomfortable" approach to music education: Re-envisioning the 'strange encounter.' Philosophy of Music Education Review 26 (1): 2445. https://doi.org/10.2979/philmusieducrevi.26.1.03

Janes, Hayley. 2021. Cultural humility in music teacher education: A virtuous vice, a vicious virtue. Action, Criticism, and Theory for Music Education 20 (1): 84-120. https://doi.org/10.22176/act20.1.84 
Hess, Juliet. 2018b. Troubling whiteness: Music education and the 'messiness' of equity work. International Journal of Music Education 36 (2): 128-44. https://doi.org/10.1177/0255761417703781

Hess, Juliet. 2019. Music education for social change: Constructing an activist music education. 1st ed. New York, NY: Routledge.

Hess, Juliet. 2021. Cultural competence or the mapping of racialized space: Cartographies of music education. Bulletin of the Council for Research in Music Education 227: 7-28. https://doi.org/10.5406/bulcouresmusedu.227.0007

Holman Jones, Stacy. 2016. Living bodies of thought: The 'critical' in critical autoethnography. Qualitative Inquiry 22 (4): 228-37. https://doi.org/10.1177/ 1077800415622509

Holman Jones, Stacy, Tony Adams, and Carolyn Ellis. 2013. Coming to know autoethnography as more than a method. In Handbook of autoethnography, edited by Stacy Holman Jones, Tony E Adams, and Carolyn Ellis, 17-48. New York, NY: Routledge.

Hook, Joshua N., Don E. Davis, Jesse Owen, Everett L. Worthington, and Shawn O. Utsey. 2013. Cultural humility: Measuring openness to culturally diverse clients. Journal of Counseling Psychology 6o (3): 353-66. https://doi.org/ 10.1037/a0032595

Hook, Joshua N., Don Davis, Jesse Owen, and Cirleen DeBlaere. 2017. Cultural humility: Engaging diverse identities in therapy. 1st ed. Washington, DC: American Psychological Association.

Hurley, David A., Sarah R. Kostelecky, and Lori Townsend. 2019. Cultural humility in libraries. Reference Services Review 47 (4): 544-55. https://doi.org/ 10.1108/RSR-06-2019-0042

Jisrawi, Athir N, and Carrie Arnold. 2018. Cultural humility and mental health care in Canadian Muslim communities (L'humilité culturelle et les soins de santé mentale jans les communautés Musulmanes Canadiennes). Canadian Journal of Counselling and Psychotherapy 52 (1): 43-64.

Keselman, Mariya, and Yasmine J. Awais. 2018. Exploration of cultural humility in medical art therapy. Art Therapy 35 (2): 77-87. https://doi.org/10.1080/ 07421656.2018.1483177

Kindall-Smith, Marsha. 2012. What a difference in 3 years! Risking social justice content in required undergraduate music education. Journal of Music Teacher Education 22 (2): 34-50. 
Leonardo, Zeus. 2004. Critical social theory and transformative knowledge: The functions of criticism in quality education. Educational Researcher 33 (6): 1118. https://doi.org/10.3102/0013189X033006011

Lerner, Justin E, and Anjali Fulambarker. 2018. Beyond diversity and inclusion: Creating a social justice agenda in the classroom. Journal of Teaching in Social Work 38 (1): 43-53. https://doi.org/10.1080/08841233.2017.1398198

Lund, Darren E., and Lianne Lee. 2015. Fostering cultural humility among preservice teachers: Connecting with children and youth of immigrant families through service-learning. Canadian Journal of Education 38 (2): 1-30. https://search.proquest.com/docview/1697674966?accountid=9851

Mackinlay, Elizabeth. 2016. In danger of relation, in danger of performance, in danger of research: An ethical conversation with Hélène Cixous and writing as intercultural arts praxis. In The Routledge international handbook of intercultural arts research, edited by Pamela Burnard, Elizabeth Mackinlay, and Kimberly Powell, 57-69. Abingdon: Routledge.

Mackinlay, Elizabeth. 2019. Critical writing for embodied approaches: Autoethnography, feminism and decoloniality. London, UK: Palgrave Macmillan.

Masters, Christie, Dea Robinson, Sally Faulkner, Eltanya Patterson, Thomas McIlraith, and Aziz Ansari. 2019. Addressing biases in patient care with the 5 Rs of cultural humility, a clinician coaching tool. Journal of General Internal Medicine. https://doi.org/10.1007/s11606-018-4814-y

McGinn, Michelle K, Sandra Acker, Marie Vander Kloet, and Anne Wagner. 2019. Dear SSHRC, what do you want? An epistolary narrative of expertise, identity, and time in grant writing. Qualitative Social Research. http://www.qualitative-research.net/index.php/fqs/article/view/3128/4331

McKoy, Constance L. 2013. Effects of selected demographic variables on music student teachers self-reported cross-cultural competence. Journal of Research in Music Education 60 (4): 375-94. https://doi.org/10.1177/00224294 12463398

Mertens, Donna M. 2009. Transformative research and evaluation. New York, NY: Guilford Press.

Moon, Sarah H., and Steven J. Sandage. 2019. Cultural humility for people of color: Critique of current theory and practice. Journal of Psychology and Theology 47 (2): 76-86. https://doi.org/10.1177/0091647119842407

Morwood, James, ed. 2005. Pocket Oxford Latin dictionary: Latin-English. 3rd ed. New York, NY: Oxford University Press.

Janes, Hayley. 2021. Cultural humility in music teacher education: A virtuous vice, a vicious virtue. Action, Criticism, and Theory for Music Education 20 (1): 84-120. https://doi.org/10.22176/act20.1.84 
Murphy, Jeffrie G. 2017. Humility as a moral virtue. In Handbook of humility: Theory, research, and applications, edited by Everett L. Worthington, Don E. Davis, and Joshua N. Hook, 1st ed., 19-32. New York, NY: Routledge.

Niknafs, Nasim. 2018. Tehran's epistemic heterotopia: Resisting music education. Philosophy of Music Education Review 26 (2): 155-75. https://doi.org/ 10.2979/philmusieducrevi.26.2.04

Niknafs, Nasim. 2020. Music education as the herald of a cosmopolitan collective imperative: On being human. International Journal of Music Education 38 (1): 3-17. https://doi.org/10.1177/0255761419859635

Porter, Steven L., Anantanand Rambachan, Abraham Vélez de Cea, Dani Rabinowtiz, Stephen Paradue, and Sherman Jackson. 2017. Religious perspectives on humility. In Handbook of humility: Theory, research, and applications, edited by Everett L. Worthington, Don E. Davis, and Joshua N. Hook, 1st ed., 6985. New York, NY: Routledge.

Rice, Timothy. 2003. The ethnomusicology of music learning and teaching. College Music Symposium 43: 65-85.

Robinson, Nicole R. 2016. Developing a critical consciousness for diversity and equity among preservice music teachers. Journal of Music Teacher Education 26 (3): 1-16. https://doi.org/10.1177/1057083716643349

Schippers, Huib. 2010. Facing the music: Shaping music education from a global perspective. New York, NY: Oxford University Press.

Siegesmund, Richard. 2018. Learning to perceive: Teaching scholartistry. In Artsbased research in education: Foundations for practice, edited by Melisa Cahnmann-Taylor and Richard Siegesmund, 2nd ed., 241-46. New York, NY: Routledge.

Spezio, Michael, Gregory Peterson, and Robert C. Roberts. 2018. Humility as openness to others: Interactive humility in the context of l'Arche. Journal of Moral Education 48 (2): 1-20. https://doi.org/10.1080/03057240.2018.1444982

Sprik, Petra, and Danielle Gentile. 2020. Cultural humility: A way to reduce LGBTQ health disparities at the end of life. American Journal of Hospice and Palliative Medicine 37 (6): 404-408. https://doi.org/10.1177/10499091198 80548

Stanley, Liz. 2004. The epistolarium: On theorizing letters and correspondences. Auto/Biography 12 (3): 201-35. https://doi.org/10.1191/o967550704abo $140 \mathrm{a}$

Janes, Hayley. 2021. Cultural humility in music teacher education: A virtuous vice, a vicious virtue. Action, Criticism, and Theory for Music Education 20 (1): 84-120. https://doi.org/10.22176/act20.1.84 
Tarrell Harris, Vincent. 2015. From with-in the black diamond: The intersections of masculinity, ethnicity, and identity-An epistolary autoethnographic exploration into the lived experiences of a Black male graduate student. Doctoral dissertation, Louisiana State University and Agriculture and Mechanical College. https://digitalcommons.lsu.edu/gradschool_dissertations/3365/

Tervalon, Melanie, and Jann Murray-García. 1998. Cultural humility versus cultural competence: A critical distinction in defining physician training outcomes in multicultural education. Journal of Health Care for the Poor and Underserved 9 (2): 117-25. https://doi.org/10.1353/hpu.2010.0233

The Truth and Reconciliation Commission of Canada. 2015. Honouring the truth, reconciling for the future: Summary of the final report of the Truth and Reconciliation Commission of Canada. http://nctr.ca/assets/reports/Final\%20Reports/Executive_Summary_English_Web.pdf

Tinkler, Alan S., and Barri Tinkler. 2016. Enhancing cultural humility through critical service-learning in teacher preparation. Multicultural Perspectives 18 (4): 192-201. https://doi.org/10.1080/15210960.2016.1222282

Tormala, Teceta Thomas, Sita G. Patel, Ellen E. Soukup, and Annette V. Clarke. 2018. Developing measurable cultural competence and cultural humility: An application of the cultural formulation. Training and Education in Professional Psychology 12 (1): 54-61. https://doi.org/10.1037/tepooo0183

Tschaepe, Mark. 2018. Cultural humility and Dewey's pattern of inquiry: Developing good attitudes and overcoming bad habits. Contemporary Pragmatism 15 (1): 152-64. https://doi.org/10.1163/18758185-01501007

Tucker, Irene. 1993. Writing home: Evelina, the epistolary novel and the paradox of property. ELH 60 (2): 419-39.

Velott, Diana, and Karin Sprow Forté. 2019. Toward health equity: Mindfulness and cultural humility as adult education. New Directions for Adult and Continuing Education 161: 57-66. https://doi.org/10.1002/ace.20311

Vesely, Colleen K., Elizabeth Levine Brown, and Swati Mehta. 2017. Developing cultural humility through experiential learning: How home visits transform early childhood preservice educators' attitudes for engaging families. Journal of Early Childhood Teacher Education 38 (3): 242-58. https://doi.org/ 10.1080/10901027.2017.1345805

Wall, Sarah. 2006. An autoethnography on learning about autoethnography. International Journal of Qualitative Methods 5 (2): 146-6o. https://doi.org/ 10.1177/160940690600500205

Janes, Hayley. 2021. Cultural humility in music teacher education: A virtuous vice, a vicious virtue. Action, Criticism, and Theory for Music Education 20 (1): 84-120. https://doi.org/10.22176/act20.1.84 
Weidman, Aaron C., Joey T. Cheng, and Jessica L. Tracy. 2018. The psychological structure of humility. Journal of Personality and Social Psychology 114 (1): 153-78. https://doi.org/10.1037/psppoooo112

Westerlund, Heidi, and Sidsel Karlsen. 2017. Knowledge production beyond local and national blindspots: Remedying professional ocularcentrism of diversity in music teacher education. Action, Criticism, and Theory for Music Education 16 (3): 78-107. https://doi.org/10.22176/act16.3.78

Winkel, Michelle. 2018. Musing on cultural humility (Miser sur l'humilité culturelle). Canadian Art Therapy Association Journal 31 (1): 1-5. https://doi.org/10.1080/08322473.2018.1458541

Worthington, Everett L., Don E. Davis, and Joshua N. Hook. 2017. Introduction: Context, overview, and guiding questions. In Handbook of humility: Theory, research, and applications, edited by Everett L. Worthington, Don E. Davis, and Joshua N. Hook, 1st ed., 1-15. New York, NY: Routledge.

\section{Notes}

${ }^{1}$ Epistolary refers to a genre of writing in which the story is told through a series of letters (Bray 2003).

${ }^{2}$ Broadly speaking, the transformative paradigm is concerned with power relations (Held 2019) and is defined by four main philosophical beliefs: a subjectivist epistemology which considers knowledge as intersubjective, experiential (Held 2019), and socially and historically constructed in the contexts of power (Mertens 2009); a historical ontology that assumes the existence of multiple socially and historically shaped realities (Held 2019), some of which are privileged over others (Mertens 2009); a social justice based axiology that positions research as a means for justice and social emancipation (Held 2019); and a dialogic/dialectical methodology (Held 2019) that considers personal transformation necessary for social transformation (Mertens 2009).

3 Leonardo (2004) presents critical social theory as a form of critique, a way to deeply engage with ideas and push them to their limit in order to highlight the relationship between social systems and individuals while contributing to the emancipation of both.

4 A few scholars (e.g., McGinn et al. 2019, Tarrell Harris 2015) have combined autoethnography (broadly, not specifically critical autoethnography) with the epistolary form. 
5 I use orientation cues to provide clarity for the reader by identifying the letter signatory and recipient prior to the beginning of each letter.

${ }^{6}$ Examples of cultural humility researchers who broadly interpret culture include: Bal and Kaur (2018), Bennett and Gates (2019), Brown, Vesely, and Dallman (2016), Keselman and Awais (2018), Tormala et al. (2018), Vesely, Brown, and Mehta (2017), and Winkel (2018).

7 Other disciplines writing about cultural humility include: nursing (e.g., Foronda 2020), psychology (e.g., Hook et al. 2017), social work (e.g., Abe 2019, Bennett and Gates 2019), health education (Velott and Forté 2019), art therapy (Bal and Kaur 2018, Keselman and Awais 2018, Winkel 2018), palliative care (Sprik and Gentile 2020), and library studies (Hurley, Kostelecky, and Townsend 2019).

8 In her literature review of culturally responsive education within music education, Bond (2017) uses the term culturally responsive education as an umbrella term which encompasses the related terms of culturally responsive teaching, culturally relevant pedagogy, culturally appropriate, mitigating cultural discontinuity, and culturally compatible.

9 Tervalon and Murray-García (1998) and Fisher-Borne, Cain, and Martin (2015) provide a list of questions for institutions to consider.

${ }^{10}$ Hinduism and Islam consider humility to be the opposite of arrogance, Buddhism contrasts humility and conceit, Judaism conceptualizes humility as a moral virtue between two extremes, and Christianity maintains that humility is the opposite of pride and vanity (Porter et al. 2017). 